\title{
A brief history of malaria chemotherapy
}

\author{
${ }^{1}$ AR Butler, ${ }^{2} \mathrm{~S}$ Khan, ${ }^{3} \mathrm{E}$ Ferguson \\ ${ }^{1}$ Honorary Reader in Medical Science; ${ }^{2,3}$ Medical Student, Bute Medical School, University of St Andrews, St Andrews, UK
}

\begin{abstract}
Malaria is one of the worst sicknesses to affect humankind. For centuries there was no specific treatment, and it was not until the seventeenth century that Spanish colonisers brought back from Peru tree bark from which quinine was later extracted. In the twentieth century, synthetic alternatives to quinine were developed. Of these, chloroquine was the most successful, but by the 1970s widespread resistance had developed and the world was left without an effective treatment for malaria. During the same decade Chinese scientists extracted from sweet wormwood plant the drug artemisinin, which has proved to be very effective against chloroquine-resistant malarial parasites. The use of a combination therapy including artemisinin has made it possible to contemplate the eradication of malaria. Efforts to produce a stable and inexpensive supply of artemisinin are under way.
\end{abstract}

KEYWORDS Artemisinin, chloroquine, combination therapy, drug resistance, malaria, quinine

DECLARATION OF INTERESTS No conflict of interests declared.

\author{
Correspondence to AR Butler, \\ Bute Medical School, \\ University of St Andrews, \\ St Andrews KYI6 9TS, UK \\ tel. +44 (0) I 334474720 \\ e-mailarb3@st-andrews.ac.uk
}

It has been suggested that more humans have died of malaria than of any other disease.' Currently, malaria kills more than a million children a year in Africa alone and its eradication is a major challenge for the international community. Not only can malaria kill people, it can also have a profound effect on the ability of survivors to work and thus inhibits economic growth. Effective chemotherapy must be part of the solution, and it is timely to review the history of drugs used in the treatment of malaria. One important group of drugs, quinine, mepacrine and chloroquine, are chemically related and each has made a major contribution to the containment of malaria. By the 1970s chloroquine-resistance had developed and there was a need for a new drug with an entirely different mode of action. Artemisinin fulfilled that need.

\section{THE MALARIAL PARASITE}

Malaria is caused by a protozoan, Plasmodium, that enters the blood stream as a consequence of a bite by an infected mosquito (Anopheles). The story of the discovery of Anopheles as the vector in the spread of malaria, by Sir Ronald Ross and Giovanni Battista Grassi, is well known, ${ }^{2}$ and it played a significant role in containing the effect of the disease. The intermittent fever, so characteristic of malaria, is due to the reproductive cycle of Plasmodium within erythrocytes. The length of the period between bouts of fever depends upon the particular species of Plasmodium in the sufferer. The most serious form of the disease, cerebral malaria, is due to $P$. falciparum and often results in death. The three other species of Plasmodium responsible for malaria in humans cause fever and lassitude and are less lethal but still serious, especially for children. There is the possibility of recrudescence in later years.
Until the nineteenth century malaria was commonplace in Europe. In Britain it was called ague; sometimes it was so serious in the East Anglian fens, the home of many mosquitoes, that there were not enough workers to bring in the harvest. Throughout southern Europe, particularly Italy, malaria was a serious problem, and it flourished in tropical regions, especially in West Africa. The disease was a major barrier to colonial expansion, as the Spanish discovered in South America - the continent from which the first effective treatment for malaria was to come.

\section{QUININE}

There is a romantic story, still to be found on the internet, ${ }^{3}$ that the Spanish learnt of the curative powers of the bark of a Peruvian tree following the sickness of the Countess of Chinchón, wife of the Spanish viceroy of Peru. According to this story, in around 1630 the countess became ill with an intermittent fever and news of this spread as far as Loxa, a city now in southern Ecuador. When the prefect of Loxa heard of this illness he immediately wrote recommending the bark of a locally found tree as a cure. He travelled to Lima with a sample and gave it to the countess, who was immediately restored to health. She acquired a stock of the bark and distributed it to the natives of Lima when they succumbed to the fever and, out of gratitude, they called it the 'countess's powder'. When she and her husband returned to Spain they introduced to Europe the use of the bark as a treatment for malaria. A sentimental novella (Zuma, by the Countess de Genlis, written in 1817) and a play (La santa virreira, or 'The saintly viceroy's wife', by the Spanish poet José María Pemán, written in 1939) are based on this story, but unfortunately it is entirely untrue. ${ }^{4}$ 
Ana de Osorio, Countess of Chinchón, died in 1625, three years before her husband went to Peru. However, in 1628 the count married Francisca Henriquez de Ribera who followed him to Peru but had robust good health during her stay, according to the detailed diary of the Viceroy's secretary. ${ }^{4}$ She died of an epidemic disease in I64I on her voyage home to Madrid and is buried in Cartagena. In the next century details of the tree were sent to Carl Linnaeus in Sweden for naming according to his new binomial system. Clearly Linnaeus had been told the story of the countess for he named the genus of tree Cinchona after her, although he got the Spanish spelling wrong. To this day it is known as cinchona bark (Figure I) or, confusingly, 'china'.

The true story of the bark's discovery and arrival in Europe is probably rather prosaic. ${ }^{2}$ The Jesuits, who did missionary work among the Peruvian Indians, learnt of the curative powers of the bark from their converts, and brought the information back to Europe. It certainly became known as Jesuits' bark, and Protestant England was deeply suspicious of it for religious reasons. Its efficacy was hotly debated; the evidence was confusing because of its adulteration with other materials by dubious suppliers.

The use of cinchona bark was firmly established in England by the activities of Sir Robert Talbor (or Tabor). As a young man,Talbor was apprenticed to an apothecary in Cambridge, where he learnt of Peruvian bark. He then studied at St John's College, and in 167I moved to Essex, which was highly malarious, and later to London. Talbor produced a secret and highly successful remedy for the ague. The Royal College of Physicians of London, who regarded him as a quack, was furious at the standing he achieved, but Talbor's success rendered him immune to derision. This success led him to treat European royalty and he died a wealthy man. In his posthumously published book, The English remedy: or Talbor's wonderful secret for cureing of agues and feavers, the secret was revealed: it was carefully sourced Peruvian bark mixed with rose leaves, lemon juice and wine.

One difficulty in the use of a material such as powdered bark is quality control. This difficulty led two French chemists, Pierre Joseph Pelletier and Jean Bienaime Caventou, to isolate from cinchona bark the 'active principle', the substance in the bark responsible for its curative properties. In 1820 they announced the isolation of an alkaloid of complex structure, which they named quinine. ${ }^{5}$ For the treatment of malaria its use, rather than that of powdered bark, quickly became the norm. Not only was it more reliable, it was also more pleasant to take.

With the colonisation of malarious parts of the world demanding large amounts of quinine, the supply from South America began to dry up. Collectors had to travel to more and more remote regions to find trees that had any bark

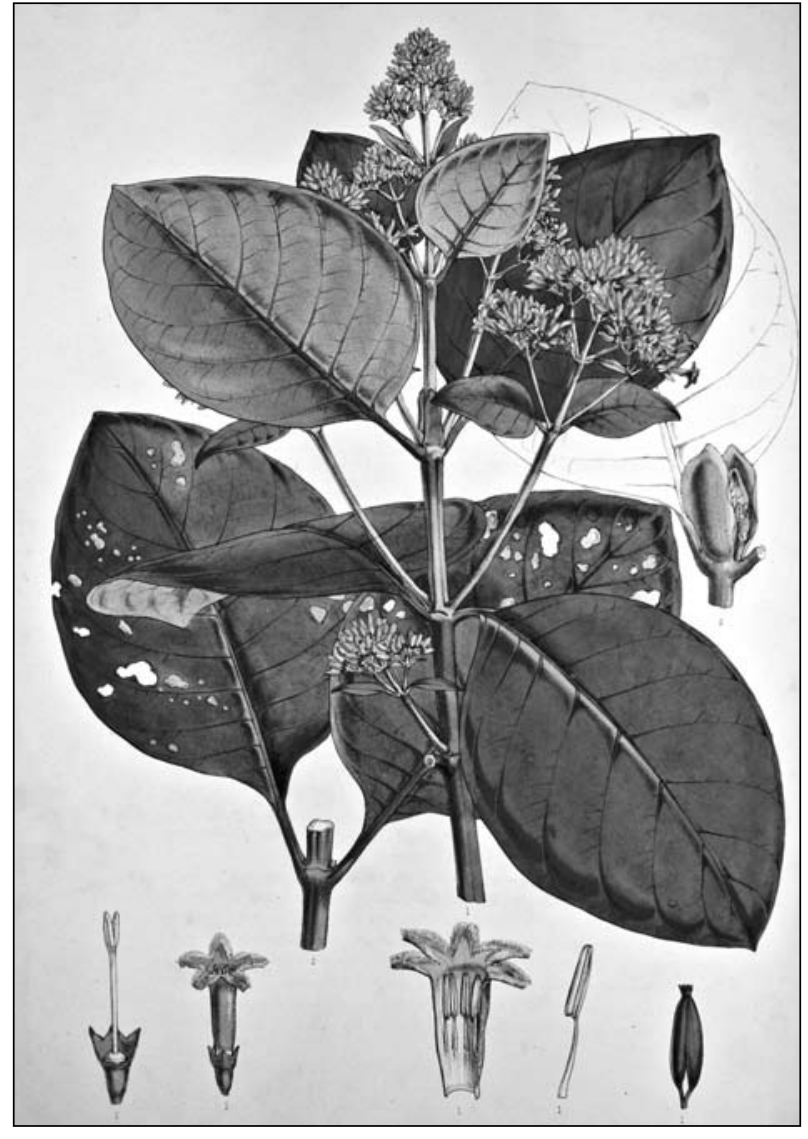

FIGURE I Cinchona succirubra, from the Nueva Quinolgia (1862), based on the botanical expedition of Ruiz and Pavón, 1777-88, with text by JE Howard and plates by W Fitch. (With thanks to the RCPE Library staff.)

left. Eventually it was decided to grow the cinchona tree in plantations and to remove the bark with care to prevent the death of the tree. An English entrepreneur, Charles Ledger, obtained seeds of the cinchona tree in $1865,{ }^{6}$ a difficult task as they are not produced every year. Saplings were raised at Kew Gardens and sent first to India and then to Java, with the latter proving a more successful location. The supply of quinine grew to satisfy the demand, and it appeared that malaria was under control.

\section{ALTERNATIVES TO QUININE}

During the First World War Germany could not obtain quinine sourced in Java and, as a consequence, German soldiers fighting in southern Europe suffered badly from malaria. To prevent this from happening again, German pharmaceutical chemists were commissioned during the 1920s to find a synthetic alternative. By 1932 they had produced mepacrine, a simplified version of quinine with some structural features changed (an acridine ring system rather than quinoline). ${ }^{7}$ For the American market it was manufactured in the USA from chemical intermediates sent from Germany.

When the Second World War broke out, trade between the USA and Germany ceased and mepacrine was no 
longer available to Americans. When Japan entered the war it quickly overran Java, cutting off the supply of quinine, so US soldiers fighting in the Pacific had no antimalarial drugs. American scientists quickly devised a manufacturing process for mepacrine and the drug was given to soldiers suffering from malaria and used as a prophylactic.

The Japanese realised that malaria was as effective as bullets in removing soldiers from the front line. They used the propaganda broadcasts of a Japanese-American lady known as Tokyo Rose to suggest that taking mepacrine made your skin go yellow, which is correct, and made you sterile, which is incorrect. (In fact, Tokyo Rose was not one person but the name given by US soldiers to a number of English-language broadcasters used by the Japanese. One of them, Iva Toguri, was found guilty of treason by a US court but pardoned by President Ford in 1977.) As a consequence of this propaganda, many US soldiers threw away their mepacrine tablets and fell victim to malaria. So many troops were removed from the front line because of this that it looked as if the Japanese might reverse American military successes.

America responded by giving this problem to a large team of academic and industrial chemists to solve. Chemical variants of sontoquine, another antimalarial drug developed by German chemists and obtained from prisoners of war in North Africa, were synthesised and examined for their therapeutic effect. ${ }^{8}$ One of them showed great promise. It was, in fact, more effective than mepacrine and sontoquine in killing the malarial parasite, was easy to manufacture and appeared to have no adverse side effects. Thus was born chloroquine. ${ }^{9}$ The required quantities eventually became available, US troops took the drug as prescribed and chloroquine played its part in bringing about the American victory against Japan.

\section{AN ATTEMPT AT MALARIA ERADICATION}

After the Second World War the international community turned its attention to the health problems of peacetime. Malaria was rampant throughout much of the developing world, and in the 1950s the World Health Organization (WHO) considered a programme for eradicating malaria similar to that used to eradicate smallpox. The auguries were good: chloroquine was highly effective against the Plasmodium parasite in humans, the new insecticide dichloro-diphenyltrichloroethane (DDT) killed the vector (Anopheles) and draining marshes removed the mosquitoes' breeding grounds. Draining the Pontine Marshes around Rome during the Mussolini era, for example, had done much to make that city malaria-free.

Initially spraying houses with DDT was a success: the number of cases of malaria in Sri Lanka, for instance, fell from 3 million in 1946 to only 29 in 1964. ${ }^{10}$ However, complications of this policy soon became apparent. DDT, thought to be a toxic material, was found to accumulate in the food chain, and mosquitoes in certain countries developed resistance. The use of DDT was eventually banned. Draining all the marshes in tropical parts of the world proved impossible and, most worryingly of all, chloroquine showed signs of decreasing efficacy. Resistance to chloroquine had been acquired by Plasmodium and gradually, during the 1970s, regions of chloroquine resistance spread throughout the world. Today, the drug is almost useless when used on its own. Resistance arose probably because of poor compliance, a major problem in bringing better healthcare to countries with little health infrastructure. The WHO, recognising the limitations of the eradication programme, renamed it Roll Back Malaria.

\section{THE HUNT FOR A CHLOROQUINE REPLACEMENT}

All the chemical variants of chloroquine appear to work by the same mechanism and so a replacement treatment required a drug of an entirely new type. Nothing in the archives of the pharmaceutical companies looked promising and tropical medicine faced one of its greatest challenges. However, an alternative as powerful as chloroquine was already emerging, but it would be some years before the drug became known in the West. China had the answer: artemisinin. Naturally the Chinese were not alone in seeking a replacement for chloroquine. The US military came up with mefloquine, now used along with a derivative of artemisinin, and halofantrine, an unsuccessful replacement.

In the 1960s China was fighting a war in the jungles of North Vietnam, a malarious region, and signs of chloroquine resistance were manifest. Unknown to the rest of the world, the Chinese government established a large research programme to find a replacement for chloroquine." In 1967, more than 500 scientists from more than 60 institutions, including chemists, pharmacologists, entomologists and doctors, were recruited by the Chinese government to the anti-malaria drug project known as Project 523. To aid recruitment and retention, scientists were relieved of the obligation to labour one day a week as agricultural workers.

A major part of Project 523 was to examine herbs used in Chinese herbal medicine as a treatment for intermittent fever. To take traditional cures seriously was something of a departure as, with the arrival of Western medicine, many Chinese intellectuals had dismissed these cures as rubbish. But Mao Zedong had insisted that traditional Chinese medicine was a 'great treasure house', a phrase immortalised in The Little Red Book, and had to be taken seriously. ${ }^{12}$ Herbs were harvested in the traditional way and subjected to extraction and analysis to see whether they contained any substance in the leaves, stem or root 
that killed the malarial parasite. At first, interest was directed at febrifugine ${ }^{13}$ from Dichroa febrifuga. This had been examined in some detail by American scientists when they were looking at an alternative to mepacrine in the 1940s. The Chinese confirmed the American view that febrifugine, although superior to quinine as an antimalarial drug, was too strong an emetic for clinical use.

\section{ARTEMISININ}

A herb frequently mentioned in Chinese materia medica (called ben cao in Chinese) as of value in the treatment of intermittent fever is Artemisia annua or sweet wormwood (qing hao in Chinese). For example, in his Handbook of prescriptions for emergency treatments dating from the third century, the alchemist and physician $\mathrm{Ge}$ Hong says of treating fever: 'Take a handful of qing hao, soak in [two litres] of water and drink.' This preparation was tried by Chinese scientists as part of Project 523, using the herb to make a tisane or infusion and carefully filtering off the solid material, as is common practice with herbal remedies. They found that the tisane had no antimalarial properties whatsoever. ${ }^{14}$

The insistence in many ben cao, published over centuries, of the value of this herb in the treatment of fever made the result difficult to understand.The matter was resolved when, in the early 1970s, three groups in Beijing, Yunnan and Shandong carried out extractions of qing hao not with water but with an organic solvent (ether, petroleum ether or acetone)." Removal of the solvent left colourless crystals that proved to be very effective in killing the malaria parasite in animal models." The extracted substance was named qing hao su or, for the benefit of Westerners, artemisinin (or, more rarely, arteannuin).

Almost immediately, the drug was tried on human malaria patients in Hainan and Shandong and found to be highly successful. By 1974 large-scale clinical trials had been launched. Artemisinin was found to have a rapid action and low toxicity and to be effective against chloroquine-resistant $P$. falciparum. As an alternative to chloroquine it looked very promising.

\section{Chemical structure}

In 1975 the determination of the chemical structure of artemisinin was started and proved to be one of the most exciting and unexpected aspects of Project 523. Elemental analysis gave it the formula $\mathrm{C}_{15} \mathrm{H}_{23} \mathrm{O}_{5}$, which indicated an unusually large number of oxygen atoms in each molecule. Nuclear magnetic resonance spectroscopy indicated that the material was a sesquiterpene, but fitting in the five oxygen atoms proved difficult (sesquiterpenes do not usually contain oxygen, except in a functional group). The matter was resolved when, in 1979, the structure was elucidated by X-ray crystallography, ${ }^{15}$ a procedure at which the Chinese excelled. Although straightforward today, at the time it was a major intellectual achievement.

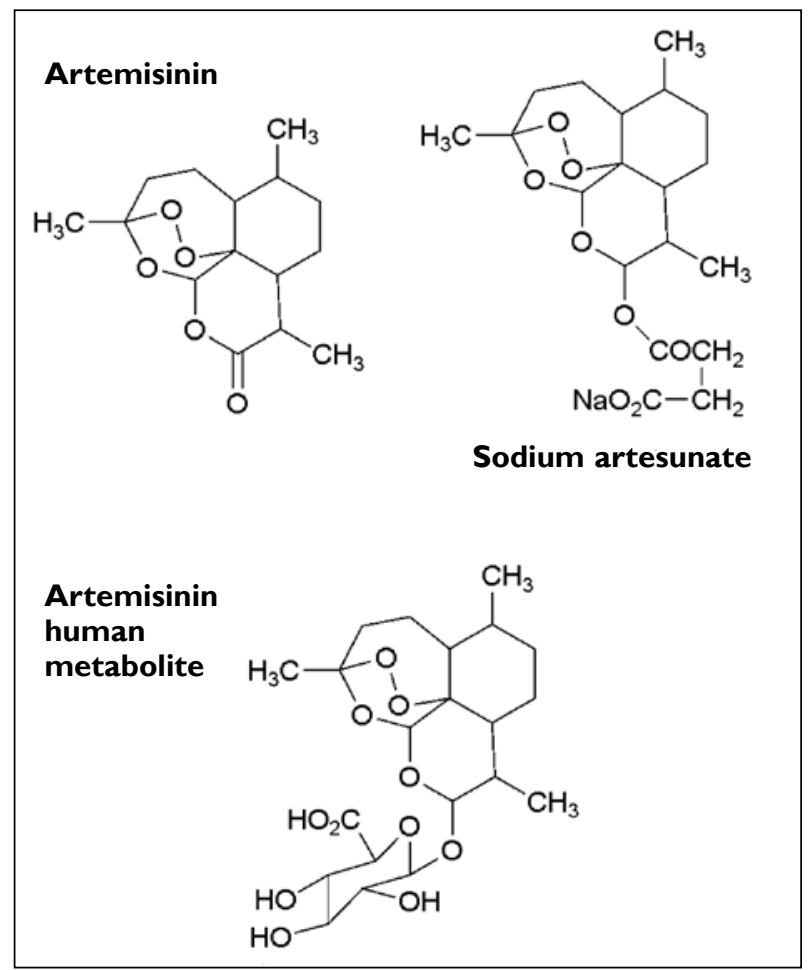

FIGURE 2 Chemical structures of artemisinin, sodium artesunate and artemisinin human metabolite.

The results were published in Chinese in a Chinese chemical journal (oddly with a subtitle in Latin, Acta Chimica Sinica). ${ }^{15}$ The molecule of artemisinin, it was claimed, consists of three fused rings, one of which has seven atoms, and there is a peroxide bridge (-O-O-) spanning one of the rings (Figure 2). Any one of these is an unusual feature in a natural product; to find all three in one molecule is astonishing. The peroxide bond in a molecule is normally very easily broken but, for some reason, it is stable in artemisinin and was later found to be the origin of its antimalarial activity. Few copies of this journal circulated in the West and this report, if it was read at all, caused little interest.

\section{Artemisinin in the West}

In 1979 the first full account of the pharmacology of artemisinin as an antimalarial drug was published in the Chinese Medical Journal, of which there was an English edition. ${ }^{16}$ The reason for this edition is not clear as the journal appears not to have circulated outside China. A dog-eared copy of the appropriate issue was seen, quite by chance, by two British malariologists, Nick White and David Warrell, working as part of the Wellcome Trust malaria team based in Bangkok. They found the claims astonishing since, during the Communist era, many exaggerated claims were made for traditional Chinese medicine and this looked like another. The chemical structure proposed for artemisinin was so unlikely that this added to their disbelief.

However, in 1981 White and Warrell travelled to Guangzhou to meet Professor Li Guoqiao, and came 
away with a precious bottle of artemisinin with which they could test the claims. When the work was repeated in Western laboratories, the Chinese claims for artemisinin were confirmed and the chemical structure proposed was found to be completely correct. The potential of artemisinin as a new, powerful antimalarial agent was quickly established and the world, particularly Africa, awaited a new onslaught against the malarial parasite. But there were delays.

Artemisia annua grows like a weed in southern China, and the Chinese authorities quickly set up factories for the extraction of artemisinin and started using it in the treatment of malaria. Having used it as a herbal remedy for 2,000 years, the Chinese felt there was no need to subject it to lengthy toxicology testing. In contrast, the regulatory authorities in the West took a different view and demanded the sort of testing to which any new drug is subject. It was to be many years before artemisinin became the drug of choice for Western agencies. It was not only the toxicology that caused delay but the possibility of resistance occurring once the drug went into general use. Chloroquine had been lost; it was vitally important that artemisinin did not follow suit. Moreover, artemisinin is an expensive drug and there was the problem of financing it for use in the developing world. It is only now that these problems appear to have been solved.

\section{Mode of action}

Artemisinin did fulfil an important criterion for a new antimalarial drug: it has an entirely different mode of action to chloroquine. The haem pigment in erythrocytes is toxic to the malarial parasite and, to protect itself, the parasite polymerises the pigment to haematin, whereas chloroquine prevents the crystallisation of the malarial pigment and its toxicity towards Plasmodium is retained. ${ }^{17}$ On the other hand, the peroxide bridge of artemisinin reacts with iron from haem to form destructive carboncentred radicals ${ }^{18}$ which kill the parasite by attacking either the sarco/endoplasmic reticulum $\mathrm{Ca}^{2+}$-ATPase ${ }^{19}$ or the parasite's DNA. ${ }^{20}$

\section{Water solubility}

Artemisinin is almost completely insoluble in water and, as a consequence, its delivery to the patient in an effective form is difficult. Initially, doses were given as a suspension in oil. A much better approach was found when artemisinin was converted into the half-ester of succinic acid (artesunate, Figure 2), ${ }^{21}$ which is much more water soluble. This is the form in which artemisinin is now generally used.

Because of its poor solubility in water it is not surprising that the early attempts at extraction of the herb using water were unsuccessful. However, the poor water solubility makes it difficult to see how its curative properties were noticed by traditional physicians using an aqueous decoction of the herb. Hsu, ${ }^{22}$ following a close reading of the ben cao, has pointed out that we are never told to remove the solid matter when drinking the decoction. The role of water seems to be to break down plant material and release particles of artemisinin. Once in the body, artemisinin can be converted into the human glucuronide metabolite ${ }^{23}$ (Figure 2), which is readily soluble in water and transported in the bloodstream.

\section{THE FUTURE}

Artemisinin is an essential element in any programme to eliminate or, even better, eradicate malaria from the malarious regions of the world. Drug resistance would be disastrous, but there is already evidence of it in malarious regions on the Thai/Cambodian border. ${ }^{24}$ The answer is always to use artemisinin in combination with other antimalarial drugs, as artemisinin combination therapy (ACT). The bonus is that the effectiveness of the treatment is greatly enhanced in ACT. The problem with ACTs is that they are more expensive than monotherapies but, if the use of monotherapies continues, resistance is almost inevitable.

In 2004, following a forthright article in The Lancet ${ }^{25}$ by a number of prominent figures in tropical medicine on the dangers of monotherapies, the WHO declared that all grants awarded for malaria treatment should be changed to specify ACTs and the major pharmaceutical companies agreed to supply ACTs for the developing world at cost price. The main problem currently is to find a stable and inexpensive supply of artemisinin. To this end the Artemisinin Enterprise has been established and is massively financed by the Bill and Melinda Gates Foundation. There are three entirely distinct projects in the enterprise:

I. The Medicines for Malaria Venture is a Swiss nonprofit organisation committed to developing new antimalarial drugs. In conjunction with the University of Nebraska Medical Center, Monash University and the Swiss Tropical Institute, the organisation is working on a number of synthetic peroxides (ozonides) that mimic artemisinin but can be readily synthesised in the laboratory. ${ }^{26}$ The first candidate (OZ277) looked very promising but failed in contact with blood. Its successor, OZ439, was developed to overcome this problem and successfully passed preclinical trials in 2008. Because of the lengthy testing required for a new drug there is bound to be a long delay, even if phase one trials for OZ439 are successful.

2. Artemisinin is too large and complex a molecule to be synthesised for drug use in a pharmaceutical factory by conventional chemical procedures. However, much can be achieved by biotechnology. Using Escherichia coli in a fermentation tank, it is possible to convert sugars into amorphadiene, which the CYP7IAVI gene converts into artemisinic acid. ${ }^{27}$ 
After extraction, artemisinic acid is converted, by standard chemical procedures, into artemisinin. A collaboration between OneWorld Health, SanofiAventis, Amyris Biotechnologies and the University of California has resulted in great progress in developing this process, but there is still quite a way to go before it replaces extraction from the herb.

3. The artemisinin content of $A$. annua is less than $1 \%$ of dry weight and this is one reason for the high cost of the drug. The Centre for Novel Agricultural Products (CNAP) at the University of York is attempting to overcome this adverse factor. Large numbers of $A$. annua plants are grown in greenhouses and, by high throughput screening, those plants with higher than usual artemisinin content are set aside and hybrids grown from them in the hope that even higher artemisinin content will be achieved. More than 23,000 plants have been assessed and a collection of 200 selected. The first hybrid plants have been grown in the greenhouse and a high artemisinin content has been found. So far the project looks very promising. ${ }^{28}$

\section{REFERENCES}

I Packard RM. The making of a tropical disease: a short history of malaria. Baltimore: Johns Hopkins University Press; 2007.

2 Rocco F. The miraculous fever-tree: malaria, medicine and the cure that changed the world. New York: HarperCollins; 2003.

3 http://www.malaria.com/info/malaria-history.php\#quinine

4 Jarcho S. Quinine's predecessor: Francesco Torti and the early history of cinchona. Baltimore: Johns Hopkins University Press; 1993.

5 Pelletier P-J, Caventou JB. Recherches chimiques sur les quinquinas. Annales de chimie et de physique 1820; 15:289-318. In French.

6 Honigsbaum M. The fever trail. London: Macmillan; 2001.

7 Sneader W. Drug prototypes and their exploitation. Chichester: John Wiley \& Sons; 1995.

8 Sneader W. Drug discovery: the evolution of modern medicines. Chichester: John Wiley \& Sons; 1985.

9 Surrey AR, Hammer HF. Some 7-substituted aminoquinoline derivatives. J Am Chem Soc 1946; 68: I I3-6. doi:I0.1021/ja01205a036

10 Tren R, Bate R. Malaria and the DDT story. London: Institute of Economic Affairs; $200 \mathrm{I}$.

II Li Y, editor. Discovery and development of new antimalarial drug (artemisinin). Shanghai: Scientific \& Technical Publishers; 2007.

12 Taylor K. Chinese medicine in early Communist China, 1945-63. London: Routledge Curzon; 2005.

I3 Butler AR, Moffett J. The antimalarial action of changshan (febrifugine). Asian Medicine:Tradition \& Modernity 2005; I:423-3I.

I4 Li Y, Wu Y-L. An over four millennium story behind qinghaosu (artemisinin). A fantastic antimalarial drug from a traditional Chinese herb. Curr Med Chem 2003: 10:2197-230. doi: I0.2 I 74/09298670334567I0

15 Liu J-M, Ni M-Y, Fan Y-F et al. [Structure and reactions of arteannuin.] Acta Chimica Sinica 1979; 37: 129-4I. In Chinese.

16 Qinghaosu Antimalaria Coordinating Research Group. Antimalarial studies of qinghaosu. Chin Med J (English edition) 1979; 92:811-16.

17 Pagola S, Stephens PW, Bohle DS et al. The structure of malaria pigment beta-haematin. Nature 2000; 404:307-10. doi:10.1038/35005I32
One important aspect of the CNAP project is that A. annua can be grown and extracted in Africa so that Africans themselves play an important part in efforts to eradicate malaria, rather than being the recipients of aid from outside. Field trials in Africa of high-yielding $A$. annua plants began in 2009. If the price of artemisinin can be stabilised it is hoped that African farmers can be persuaded to give over part of their land to growing $A$. annua. As well as selective breeding, CNAP is mapping the genetic code of $A$. annua in an effort to locate key genes and molecular markers that control the artemisinin content. This will allow the identification of suitable plants at a very early stage. ${ }^{29}$

A plentiful and inexpensive supply of artemisinin is essential for the ready availability of ACTs in Africa's fight against malaria. Let us hope that one, if not more, of the Artemisinin Enterprise's projects come to fruition. The journey of artemisinin from the arcane world of Chinese herbal medicine to the world of modern high technology is a curious one, but may hold the key to the eradication of malaria.

18 Wu W-M, Wu Y, Wu Y-L et al. Unified mechanistic framework for the $\mathrm{Fe}(\mathrm{II})$-induced cleavage of qinghaosu and derivatives/analogues. The first spin-trapping evidence for the previously postulated secondary C-4 radical. J Am Chem Soc 1998; 120:3316-25. doi: $10.1021 / j a 9730800$

19 Eckstein-Ludwig U,Webb RJ, van Goethem ID et al. Artemisinins target the SERCA of Plasmodium falciparum. Nature 2003; 424:95761. doi:10.1038/nature01813

20 Wu W-M, Yao Z-J, Wu Y-L et al. Ferrous ion induced cleavage of the peroxy bond in qinghaosu and its derivatives and the DNA damage associated with this process. Chem Comm 1996; 18:2213-4. doi:I0.1039/cc99600022I3

21 Lin AJ, Lee M, Klayman DL. Antimalarial activity of new water soluble dihydroartemisinin derivatives. 2. Stereospecificity of the ether side chain. J Med Chem 1989; 32:1249-52. doi:10.102I/ im00I26a0I7

22 Hsu E. Diverse biologies and experimental continuities. Did the ancient Chinese know that qinghao had antimalarial properties? Canad Bull Med Hist 2009; 26:203-13.

23 Maggs JL, Batty KT, llett KF et al. Isomerization in the human urine of a glucuronide of the antimalarial endoperoxide drug dihydroartemisinin. Br J Clin Pharmacol 1998; 46:293P.

24 Shay C. In a malaria hot spot, resistance to a key drug. Time 14 November 2009. Available at: http://www.time.com/time/world/ article/0,8599, 1939239,00.html

25 Attaran A, Barnes KI, Curtis C et al.WHO, the Global Fund, and medical malpractice in malaria treatment. Lancet 2004; 363:23740. doi:I0.10I6/S0I40-6736(03)|5330-5

26 Vennerstrom JL, Acton N, Lin Al et al. Peroxides as oxidant malarials. Drug Des Deliv 1989; 4:45-54.

27 Ro D-K, Paradise EM, Ouellet $M$ et al.Production of the antimalarial drug precursor artemisinic acid in engineered yeast. Nature 2006; 440:940-3. doi: 10.1038/nature04640

28 CNAP update number 5. Available from: http://www.york.ac.uk/ org/cnap/artemisiaproject/projectUpdates.htm

29 Graham IA, Besser K, Blumer S et al. The genetic map of Artemisia annua $\mathrm{L}$. identifies loci affecting yield of the antimalarial drug artemisinin. Science 20I0; 327:328-3I. doi:I0.II26/science.II826I2 